\title{
Effect of foot orthoses on lower extremity kinetics during running: a systematic literature review Andrew McMillan* and Craig Payne
}

\author{
Address: Department of Podiatry, La Trobe University, Bundoora, Vic. 3086, Australia \\ Email: Andrew McMillan* - am3mcmillan-sexton@students.latrobe.edu.au; Craig Payne - C.Payne@latrobe.edu.au \\ * Corresponding author
}

Published: 17 November 2008

Journal of Foot and Ankle Research 2008, I:I3 doi:10.1 I86/I757-II46-I-13

This article is available from: http://www.jfootankleres.com/content/l/I/I3

(C) 2008 McMillan and Payne; licensee BioMed Central Ltd.

This is an Open Access article distributed under the terms of the Creative Commons Attribution License (http://creativecommons.org/licenses/by/2.0), which permits unrestricted use, distribution, and reproduction in any medium, provided the original work is properly cited.
Received: 12 September 2008

Accepted: 17 November 2008

\begin{abstract}
Background: Throughout the period of one year, approximately $50 \%$ of recreational runners will sustain an injury that disrupts their training regimen. Foot orthoses have been shown to be clinically effective in the prevention and treatment of several running-related conditions, yet the physical effect of this intervention during running remains poorly understood. The aim of this literature review was therefore to evaluate the effect of foot orthoses on lower extremity forces and pressure (kinetics) during running.
\end{abstract}

Methods: A systematic search of electronic databases including Medline (1966-present), CINAHL, SportDiscus, and The Cochrane Library occurred on 7 May 2008. Eligible articles were selected according to pre-determined criteria. Methodological quality was evaluated by use of the Quality Index as described by Downs \& Black, followed by critical analysis according to outcome variables.

Results: The most widely reported kinetic outcomes were loading rate and impact force, however the effect of foot orthoses on these variables remains unclear. In contrast, current evidence suggests that a reduction in the rearfoot inversion moment is the most consistent kinetic effect of foot orthoses during running.

Conclusion: The findings of this review demonstrate systematic effects that may inform the direction of future research, as further evidence is required to define the mechanism of action of foot orthoses during running. Continuation of research in this field will enable targeting of design parameters towards biomechanical variables that are supported by evidence, and may lead to advancements in clinical efficacy.

\section{Background}

Throughout the period of one year, approximately $50 \%$ of recreational runners will sustain an injury that disrupts their training regimen $[1,2]$. Intrinsic risk factors shown to consistently correlate with running injury include previous injury [3-7] and limited running experience [3,8-10]. Support for an association between foot morphology and specific running-related injuries has also been shown in several clinical studies. For example, the association between pes cavus and lower extremity stress fracture is well supported [7,11-15], while further evidence demonstrates an association between pes planus and medial tibial stress syndrome $[11,13,16-18]$. An association between foot posture and plantar fasciitis in the running population is less convincing [7,19-21], however Irving et al. [22] recently found pronated foot alignment to be a risk factor 
for this condition. An association between foot pronation and patellofemoral pain has also been suggested in the literature $[7,11,23,24]$, however this relationship has been contested by several prospective and cross-sectional cohort studies [25-30].

Patellofemoral pain syndrome is reported to be the most commonly encountered running-related injury $[1,31,32]$, accounting for between $11 \%$ and $16 \%$ of conditions $[31,32]$. The incidence of stress fracture has been found to vary from $4 \%$ to $15 \%$ of running injuries, with the tibia, navicular, and femur being the most common sites [3133]. Medial tibial stress syndrome and plantar fasciitis have been found to have similar rates of incidence, accounting for between $4 \%$ and $8 \%$ of running-related injuries $[31,32]$.

The clinical effectiveness of foot orthoses has been demonstrated in clinical trials for either the prevention [3437] or treatment [38-43] of the running-related conditions described above. However at the time of writing, no systematic review evaluating the mechanism of action of foot orthoses during running had been published. This limitation has consequences in relation to dispensing foot orthoses, as without an understanding of the intervention effect, the presumed action may not be produced as intended.

Several literature reviews have evaluated the effects of foot orthoses on lower extremity position and movement (kinematics) without a systematic search strategy [44-47].
These reviews have described the effect of foot orthoses on kinematic variables to be small and non-systematic. As a result, research into the biomechanics of foot orthoses has increasingly focussed on lower extremity force and pressure (kinetics). However, the effect of foot orthoses on kinetic variables during running had not been systematically evaluated at the time of writing. The aim of this literature review was therefore to systematically collect all published research in this topic, and critically evaluate the methodology and experimental findings.

\section{Methods}

A systematic search of electronic databases including Medline (1966-present), CINAHL, SportDiscus, and The Cochrane Library occurred on 7 May 2008. The search terms foot orthotic $\$$, foot orthos $\$$ s and insole $\$$ were used in conjunction with the terms kinetic\$, biomechanic\$, running, and force $\$$ in various combinations (Table 1 ). The search strategy was limited to articles published in the English language. Targeted searching of relevant journals also occurred following bibliographic review of retrieved articles.

Articles accepted for inclusion were required to be published in peer-reviewed journals, and report the findings of original experimental or quasi-experimental research. Articles were excluded according to the following criteria:

- Measurement of effects during walking

- Kinematic variables exclusively investigated.

Table I: Search terminology and generated citations according to database title.

\begin{tabular}{|c|c|c|c|c|c|}
\hline Search Term & Medline & CINAHL & SPORT Discuss & Cochrane Library & Total \\
\hline foot orthotic\$ AND kinetic\$ & 5 & 7 & 7 & 2 & 21 \\
\hline foot orthos\$s AND kinetic\$ & 29 & 50 & 22 & 4 & 105 \\
\hline Insole $\$$ AND kinetic $\$$ & 9 & 9 & 14 & I & 33 \\
\hline foot orthotic\$ AND biomechanic\$ & 17 & 21 & 41 & 13 & 92 \\
\hline foot orthos\$s AND biomechanic\$ & 121 & 185 & 94 & 14 & 414 \\
\hline Insole $\$$ AND biomechanic $\$$ & 73 & 26 & 112 & 9 & 220 \\
\hline foot orthotic $\$$ AND running & 7 & 11 & 25 & 16 & 59 \\
\hline foot orthos\$s AND running & 15 & 42 & 21 & 13 & 91 \\
\hline Insole \$ AND running & 24 & 15 & 59 & 7 & 105 \\
\hline Orthotic $\$$ AND running AND biomechanic $\$$ & 35 & 17 & 71 & 7 & 130 \\
\hline Orthos $\$$ s AND running AND biomechanic $\$$ & 21 & 36 & 34 & 6 & 97 \\
\hline Insole $\$$ AND running AND biomechanic\$ & 12 & 6 & 26 & 3 & 47 \\
\hline foot orthotic $\$$ AND force $\$$ & 3 & 3 & 6 & 18 & 30 \\
\hline foot orthos $\$$ s AND force $\$$ & 52 & 73 & 33 & 21 & 179 \\
\hline Insole $\$$ AND force $\$$ & 67 & 28 & 75 & 8 & 178 \\
\hline Total & 490 & 529 & 640 & 142 & $180 \mid$ \\
\hline
\end{tabular}


- Orthoses other than foot orthoses exclusively investigated.

Electromyographic (EMG) studies were also excluded, as they measured biophysical variables that are distinct from kinetics. Furthermore, in accordance with definitions contained in the Australian Podiatry Council's 'Guidelines on Orthotic Therapy' [48], studies investigating the effects of insoles limited to cushioning properties were also excluded. Titles and abstracts of all citations generated by the search were assessed by one author according to the inclusion and exclusion criteria above, with articles printed in full-text as required.

All articles accepted for review underwent methodological assessment to evaluate the research quality. This process occurred in accordance with the Quality Index described by Downs \& Black [49], in which a systematic checklist is used to evaluate the external and internal validities of clinical trials. This checklist was adjusted to exclude 12 questions deemed to be less relevant to the articles assessed in this review, resulting in the retention of 15 questions (Table 2). Additionally, the protocol and specific design features of each study were extracted, with particular focus on condition randomisation, participant running experience, condition acclimatisation and orthosis design.

Following methodological assessment, articles were grouped and discussed according to kinetic outcome variables. However the evaluation was unable to be conducted as a meta-analysis, due to heterogenicity in experimental designs.

\section{Results}

The search process generated a total 1801 citations for initial screening (Table 1), of which 1770 were excluded on review of title and abstract. 31 articles were printed in fulltext for further consideration, of which 10 were eligible for final inclusion (Table 3). All included articles were published between 1991 and 2008, and reported the findings of laboratory-based research with a repeated measures design.

The mean Quality Index Score for the articles was $64 \%$ $(S D=10.5)$, demonstrating limited overall quality (Table 2). The majority of studies demonstrated inadequacy in selecting a representative sample and in the description of participant characteristics, while none attempted to blind subjects or investigators. Four studies included participants without reporting estimates of weekly running mileage. Additionally, several trials failed to randomise the sequence in which conditions occurred, thereby exposing the findings to order effects.
Despite the limitations described above, all studies provided adequate descriptions of outcome variables and orthosis design parameters, and reported findings with estimates of random variability. Furthermore, all used standardised footwear and running speeds during experimental conditions.

\section{Loading Rate and Peak Impact Force}

The vertical loading rate is the vertical impact force quantified with reference to time, and is normally reported as either the maximum or average in Newtons per second $(\mathrm{N} / \mathrm{s})$ [50]. Five articles measured this variable by forceplate analysis [51-55].

A study of 8 military recruits [52] found a significant decrease in both the average and peak loading rates while running in prefabricated foot orthoses. Despite subjects in this trial wearing military boots, these findings correspond with two trials $[53,55]$ in which foot orthoses were shown to significantly reduce the loading rates of runners with both normal and excessively pronated foot posture. However, two trials investigating the effects of custommoulded foot orthoses $([51,54]$ found no significant effect on loading rates during running.

In addition to investigating loading rates, four of the studies above measured the peak impact force magnitude [52$55]$. This variable is the maximum vertical ground-reaction force (GRF) during the initial loading phase of stance $[50]$, and is thereby closely related to the loading rate. This relationship is demonstrated in the findings of these trials, with three studies reporting both variables to be either significantly $[52,55]$ or insignificantly $[54]$ reduced by foot orthoses. In contrast, Laughton et al. [53] found an inverse relationship between these variables (Table 4).

Comparison of the foot orthoses used in these trials fails to demonstrate correlations with orthosis design, as conflicting data was collected by use of orthoses with similar features (Table 4). Furthermore, as the Quality Index Scores of the above studies are also very similar, weighting of evidence based on methodological quality would result in equivalent findings (Table 4). An approximately equal proportion of studies with systematic and non-systematic findings failed to ensure that only experienced runners were included, subjects were allocated a period of acclimatisation, and the order of conditions was randomised (Table 4). Furthermore, all trials involved participants running over-ground at very similar speeds, with data collected by comparable equipment.

As the trials described above have similar methodological quality and research designs, current evidence suggests that foot orthoses have non-systematic effects on the loading rate and peak impact force during running. 
Table 2: Quality assessment of included articles (adapted from Downs \& Black [49])

\begin{tabular}{|c|c|c|c|c|c|c|c|c|c|c|c|}
\hline & Reference: & {$[51]$} & [52] & [58] & [53] & {$[54]$} & {$[60]$} & {$[55]$} & [59] & [56] & [57] \\
\hline I & Is the hypothesis/aim of the study clearly described? & 1 & 1 & 1 & 1 & 1 & 1 & 1 & 1 & 1 & 1 \\
\hline 2 & $\begin{array}{l}\text { Are the main outcomes to be measured clearly described in the Introduction } \\
\text { or Methods section? }\end{array}$ & 1 & 1 & 1 & 1 & 1 & 1 & 1 & 1 & 1 & 1 \\
\hline 3 & $\begin{array}{l}\text { Are the characteristics of the patients included in the study clearly described } \\
?\end{array}$ & 0 & 0 & 0 & 0 & 1 & 1 & 1 & 0 & 0 & 0 \\
\hline 4 & Are the interventions of interest clearly described? & 1 & 1 & 1 & 1 & 1 & 1 & 1 & 1 & 1 & 1 \\
\hline 5 & Are the main findings of the study clearly described? & 1 & 1 & 1 & 1 & 1 & 1 & 1 & 1 & 1 & 1 \\
\hline 6 & $\begin{array}{l}\text { Does the study provide estimates of the random variability in the data for the } \\
\text { main outcomes? }\end{array}$ & 1 & 1 & 1 & 1 & 1 & 1 & 1 & 1 & I & 1 \\
\hline 7 & $\begin{array}{l}\text { Have actual probability values been reported (e.g. } 0.035 \text { rather than }<0.05) \\
\text { for the main outcomes except where the probability value is less than } 0.001 \text { ? }\end{array}$ & I & 0 & I & 1 & I & 0 & I & 0 & I & I \\
\hline 8 & $\begin{array}{l}\text { Were the subjects asked to participate in the study representative of the } \\
\text { entire population from which they were recruited? }\end{array}$ & 0 & 0 & 1 & 0 & 0 & 0 & 0 & 0 & I & 0 \\
\hline 9 & $\begin{array}{l}\text { Were those subjects who were prepared to participate representative of the } \\
\text { entire population from which they were recruited? }\end{array}$ & 0 & 0 & 0 & 1 & 0 & 0 & 0 & 0 & I & 0 \\
\hline 10 & $\begin{array}{c}\text { Was an attempt made to blind study subjects to the intervention they have } \\
\text { received? }\end{array}$ & 0 & 0 & 0 & 0 & 0 & 0 & 0 & 0 & 0 & 0 \\
\hline 11 & $\begin{array}{l}\text { Was an attempt made to blind those measuring the main outcomes of the } \\
\text { intervention? }\end{array}$ & 0 & 0 & 0 & 0 & 0 & 0 & 0 & 0 & 0 & 0 \\
\hline 12 & $\begin{array}{l}\text { If any of the results of the study were based on "data dredging", was this } \\
\text { made clear? }\end{array}$ & I & I & 1 & 1 & I & 0 & I & I & I & 1 \\
\hline 13 & Were the statistical tests used to assess the main outcomes appropriate? & 1 & 1 & 1 & 1 & 1 & 0 & 1 & 1 & 1 & 1 \\
\hline 14 & Were the main outcome measures used accurate (valid and reliable)? & 1 & 1 & 1 & 1 & 1 & 0 & 1 & 1 & 1 & 1 \\
\hline \multirow[t]{3}{*}{15} & Were study subjects randomised to intervention groups? & 1 & 0 & 0 & 1 & 0 & 0 & 1 & 1 & 0 & 1 \\
\hline & Quality Index Score (max score = I5) & 10 & 8 & 10 & $\mathrm{II}$ & 10 & 6 & 11 & 9 & II & 10 \\
\hline & Quality Index \% & 67 & 53 & 67 & 73 & 67 & 40 & 73 & 60 & 73 & 67 \\
\hline
\end{tabular}

( $0=$ no/unable to determine, $I=$ yes $)$

\section{Rearfoot Inversion Moment}

A resultant joint moment is the rotational force generated at the joint axis by a force applied to a biomechanical lever-arm, and is calculated by multiplying the applied force (Newtons) by the length (metres) of the lever-arm by which it acts [50]. Three articles collected data for the rearfoot inversion moment [54,56,57], all used custommoulded orthoses with subjects running over a force plate under 3-dimensional video analysis.
All three trials investigating the effect of foot orthoses on rearfoot inversion moments demonstrate a consistent trend. Two of these trials $[54,57]$ report a statistically significant effect, however the trial by Williams et al. [57] compared the effect of orthoses with $4^{\circ}$ rearfoot posting to orthoses with $25^{\circ}$ posting, finding only the latter to produce a significant effect. However, this discrepancy may be due to the relatively small sample size of this trial $(\mathrm{n}=11)$, as an average $27 \%$ decrease in rearfoot inversion 
Table 3: Articles selected for inclusion

\begin{tabular}{|c|c|c|c|c|}
\hline Author & Date & Title & Journal & Ref \\
\hline Butler et al. & 2003 & Dual function foot orthosis: effect on shock and control of rearfoot motion. & Foot Ankle Int. & [5I] \\
\hline Dixon & 2007 & $\begin{array}{l}\text { Influence of a commercially available orthotic device on rearfoot eversion and vertical } \\
\text { ground reaction force when running in military footwear. }\end{array}$ & Mil Med. & {$[52]$} \\
\hline Dixon \& McNally & 2008 & $\begin{array}{l}\text { Influence of orthotic devices prescribed using pressure data on lower extremity } \\
\text { kinematics and pressures beneath the shoe during running. }\end{array}$ & Clin Biomech. & {$[58]$} \\
\hline Laughton et al. & 2003 & Effect of strike pattern and orthotic intervention on tibial shock during running. & J Appl Biomech. & [53] \\
\hline MacLean et al. & 2006 & $\begin{array}{l}\text { Influence of a custom foot orthotic intervention on lower extremity dynamics in healthy } \\
\text { runners. }\end{array}$ & Clin Biomech. & {$[54]$} \\
\hline McPoil \& Cornwall & 1991 & Rigid versus soft foot orthoses: a single subject design. & JAPMA & [60] \\
\hline Mundermann et al. & 2003 & Foot orthotics affect lower extremity kinematics and kinetics during running. & Clin Biomech. & [55] \\
\hline Nigg et al. & 2003 & $\begin{array}{c}\text { Effect of shoe inserts on kinematics, center of pressure, and leg joint moments during } \\
\text { running. }\end{array}$ & Med Sci Sports Exerc. & [59] \\
\hline Stackhouse et al. & 2004 & Orthotic intervention in forefoot and rearfoot strike running patterns. & Clin Biomech. & [56] \\
\hline Williams et al. & 2003 & Effect of inverted orthoses on lower-extremity mechanics in runners. & Med Sci Sports Exerc. & {$[57]$} \\
\hline
\end{tabular}

moment was measured with the $4^{\circ}$ orthosis. These findings are similar to those of the trial that did not reach statistical significance [56], in which a $24 \%$ decrease in rearfoot inversion moment was measured, and a post-hoc power calculation revealed that additional subjects were required.

The findings of these studies are consistent despite differences in subject foot morphology, with two trials only including healthy subjects $[54,56]$, and the remaining trial [57] only including subjects with a clinical need for the orthoses. Additionally, while two of these trials were exposed to order effects, the Quality Index Scores are higher than the overall mean for the trials included in this review (Table 5).

These trials suggest that foot orthoses have a systematic effect on the rearfoot inversion moment of runners with both normal and excessively pronated foot posture, and suggest a linear relationship between degree of rearfoot posting and effect magnitude. Furthermore, the findings of these trials contribute significantly to current understanding of the mechanism of action of foot orthoses during running.

\section{Plantar Pressure}

Plantar pressure may be described as the quantity of force acting over the plantar surface area of the foot, and is normally reported as Newtons per centimetre squared (N/ $\mathrm{cm} 2$ ) [50]. Two articles $[58,59]$ collected data for plantar pressure during running in custom-moulded orthoses, with conflicting findings.

A trial of 22 runners with recurring lower limb injury found medially-posted foot orthoses to have a consistent effect on plantar pressure during running [58]. This trial used a digital masking technique in which the plantar rearfoot was subdivided into medial and lateral segments,

Table 4: Quality of articles reporting findings for loading rate and peak impact force.

\begin{tabular}{|c|c|c|c|c|c|c|c|}
\hline Ref. & Orthosis Design & $\begin{array}{l}\text { Significant effect } \\
\text { on loading rate }\end{array}$ & $\begin{array}{l}\text { Significant effect on } \\
\text { peak impact force }\end{array}$ & $\begin{array}{l}\text { Quality Index } \\
\text { Score (\%) }\end{array}$ & $\begin{array}{c}\text { Condition } \\
\text { Randomisation }\end{array}$ & $\begin{array}{l}\text { Experienced } \\
\text { Runners }\end{array}$ & $\begin{array}{l}\text { Acclimatizati } \\
\text { on Period }\end{array}$ \\
\hline [5I] & $\begin{array}{c}\text { Custom-moulded rigid \& soft: } 6 \\
\text { degrees rearfoot post }\end{array}$ & $x$ & $\mathrm{n} / \mathrm{a}$ & 67 & $\checkmark$ & $x$ & $\checkmark$ \\
\hline [52] & $\begin{array}{l}\text { Prefabricated semi rigid: full } \\
\text { length }\end{array}$ & $\checkmark$ & $\checkmark$ & 53 & $x$ & $x$ & $x$ \\
\hline [53] & $\begin{array}{l}\text { Custom-moulded semi-rigid: } 6 \\
\text { degrees rearfoot post }\end{array}$ & $\checkmark$ & $x$ & 73 & $\checkmark$ & $x$ & $\checkmark$ \\
\hline [54] & $\begin{array}{c}\text { Custom-moulded semi-rigid: } 5 \\
\text { degrees rearfoot post }\end{array}$ & $x$ & $x$ & 67 & $x$ & $\checkmark$ & $x$ \\
\hline [55] & $\begin{array}{l}\text { Custom-moulded semi-rigid: nil } \\
\text { post \& } 6 \mathrm{~mm} \text { rearfoot/forefoot } \\
\text { post }\end{array}$ & $\checkmark$ & $\checkmark$ & 73 & $\checkmark$ & $\checkmark$ & $x$ \\
\hline
\end{tabular}


Table 5: Quality of articles reporting findings for rearfoot inversion moment.

\begin{tabular}{|c|c|c|c|c|c|}
\hline Ref. & Orthosis Design & Quality Index Score (\%) & Condition randomisation & Experienced runners & Acclimatization period \\
\hline [54] & $\begin{array}{c}\text { Custom-moulded semi-rigid: } 5 \\
\text { degrees rearfoot post }\end{array}$ & 67 & $x$ & $\checkmark$ & $x$ \\
\hline [56] & $\begin{array}{c}\text { Custom-moulded semi-rigid: } 6 \\
\text { degrees rearfoot post }\end{array}$ & 73 & $x$ & $\checkmark$ & $\checkmark$ \\
\hline [57] & $\begin{array}{c}\text { Custom-moulded semi-rigid: } 4 \\
\text { degrees \& 15-25 degrees rearfoot } \\
\text { post }\end{array}$ & 67 & $\checkmark$ & $\checkmark$ & $\checkmark$ \\
\hline
\end{tabular}

while plantar pressures beneath the metatarsal heads were measured individually. In comparison to control, this trial found a considerable increase in plantar pressure under the lateral surface of the foot with medially-posted orthoses. In contrast, an earlier trial [59] found laterallyposted orthoses to cause deviation of plantar pressure in the same direction, and medially posted orthoses to produce only random effects.

In addition to variations in orthosis design between these two trials (Table 6), there are differences in the technical equipment used, with one trial using a pressure-plate [58] and the other an insole system [59]. This discrepancy may obscure the comparison of results between these two trials, as a pressure-plate measures pressure at the shoe/ ground interface, while an insole sensor detects pressure at the foot/orthosis interface.

The findings of these trials suggest that plantar pressure beneath the lateral foot may be increased while running in foot orthoses with both medial and lateral posting designs, and that detection of effects may depend on the interface at which pressure is measured. Current evidence therefore suggests that foot orthoses have a variable effect on medio-lateral plantar pressure distribution during running, and that further research into this parameter is required.

\section{Timing of Peak Impact Force}

In addition to reporting the magnitude of peak impact force, one trial [52] measured the timing of peak impact force during running. The findings of this trial demonstrate a systematic delay in the timing of peak impact force with the use of full-length prefabricated foot orthoses. While current evidence for the effect of foot orthoses on this variable is limited to one trial, the findings suggest that further research into the timing of plantar force variables may be productive.

\section{Force/Time Integral}

The force/time integral is also known by the term impulse, and is calculated as the area below the plantar force/time curve [50]. One trial investigated the effects of foot orthoses on the force/time integral during running [60]. While the results of this trial demonstrate a reduction in this variable with custom-moulded orthoses, the singlesubject design and poor methodological quality limit the implications of these findings (Table 7). Current evidence for the effect of foot orthoses on the force/time integral during running is therefore insufficient, and unable to suggest systematic changes. Further research is required to investigate this parameter adequately.

\section{Conclusion}

The studies included in this review are of low methodological quality, with the most confounding error being the lack of randomisation to the order of conditions. The most widely reported kinetic outcomes were loading rate and impact force, however the effect of foot orthoses on these variables remains unclear. In contrast, current evidence suggests that a reduction in the rearfoot inversion

Table 6: Quality of articles reporting findings for plantar pressure.

\begin{tabular}{|c|c|c|c|c|c|c|}
\hline Ref. & Orthosis Design & Quality Index Score (\%) & $\mathrm{n}=$ & Condition randomisation & Experienced runners & Acclimatization period \\
\hline [58] & $\begin{array}{l}\text { Custom-moulded EVA with } \\
\text { shell: high normal and low arch } \\
\text { contour }\end{array}$ & 67 & 22 & $x$ & $\checkmark$ & $x$ \\
\hline [59] & $\begin{array}{c}\text { Custom-moulded EVA: } 4.5 \mathrm{~mm} \\
\text { lateral post }\end{array}$ & 60 & 15 & $\checkmark$ & $x$ & $x$ \\
\hline
\end{tabular}


Table 7: Methodological quality of trial reporting findings for force/time integral.

\begin{tabular}{|c|c|c|c|c|c|c|}
\hline Ref. & Orthosis Design & Quality Index Score (\%) & $\mathrm{n}=$ & Condition randomisation & Experienced runners & Acclimatization period \\
\hline [60] & $\begin{array}{l}\text { Custom-moulded soft: direct } \\
\text { moulded }\end{array}$ & 40 & 1 & $x$ & $\checkmark$ & $\checkmark$ \\
\hline
\end{tabular}

moment is the most consistent kinetic effect of foot orthoses during running.

This systematic review has evaluated the evidence surrounding the effects of foot orthoses on lower extremity kinetics during running. The findings demonstrate systematic effects that may inform the direction of future research in this field, as further evidence is required to define the mechanism of action of foot orthoses during running. Continuation of research in this field will enable targeting of design parameters towards biomechanical variables that are supported by evidence, and may lead to advancements in clinical efficacy.

\section{Competing interests}

The authors declare that they have no competing interests.

\section{Authors' contributions}

AM conceived the study design, conducted the systematic review, interpreted the findings and drafted the manuscript. CP reviewed the manuscript and provided academic support throughout.

\section{Author's information}

$\mathrm{AM}$ is an Honours student within the Department of Podiatry, La Trobe University. CP is a Senior Lecturer within the Department of Podiatry, La Trobe University.

\section{Acknowledgements}

Essential materials and resources were provided by the Department of Podiatry, La Trobe University.

\section{References}

I. Fredericson M, Anuruddh M: Epidemiology and Aetiology of Marathon Running Injuries. Sports Medicine 2007, 37(45):437-439.

2. McKean K, Manson N, Stanish W: Musculoskeletal Injury in the Masters Runners. Clinical Journal of Sport and Medicine 2006, 16:149-154.

3. van Middelkoop M, Kolkman J, van Ochten J, Bierma-Zeinstra S, Koes B: Course and Predicting Factors of Lower-Extremity Injuries After Running a Marathon. Clinical Journal of Sport and Medicine 2007, I 7:25-30.

4. van Gent R, van Middelkoop M, van Os A, Bierma-Zeinstra S, Koes B: Incidence and Determinants of Lower Extremity Running Injuries in Long Distance Runners: A Systematic Review. British Journal of Sports Medicine 2007, 41:469-480.

5. Hootman J, Macera C, Ainsworth B, Martin M, Addy C, Blair S: Predictors of Lower Extremity Injury Among Recreationally Active Adults. Clinical Journal of Sport and Medicine 2002, I 2:99-106.

6. Rauh M, Koepsell T, Rivara F, Margherita A, Rice S: Epidemiology of Musculoskeletal Injuries Among High School Cross-Country Runners. American Journal of Epidemiology 2006, I 63: I5I-I59.
7. Murphy DF, Connolly DAJ, Beynnon BD: Risk factors for lower extremity injury: a review of the literature. (Review). British Journal of Sports Medicine 2003, 37(I):.

8. Satterthwaite P, Norton R, Larmer P, Robinson E: Risk Factors for Injuries and Other Health Problems Sustained in a Marathon. British Journal of Sports Medicine 1999, 33:22-26.

9. Knapik J, Sharp M, Canham-Chervak M, Hauret K, Patton J, Jones B: Risk Factors for Training-Related Injuries Among Men and Women in Basic Combat Training. Medicine \& Science in Sports \& Exercise 200I, 33(6):946-954.

10. Chorley J, Cianca J, Divine J, Hew T: Baseline Injury Risk Factors for Runners Starting a Marathon Training Program. Clinical Journal of Sport and Medicine 2002, I 2: I8-23.

II. Williams D, McClay I, Hamill J: Arch structure and injury patterns in runners. Clinical biomechanics 200I, I 6:34I-347.

12. Korpelainen R, Orava S, Karpakka J, Siira P, Hulkko A: Risk Factors for Recurrent Stress Fractures in Athletes. The American Journal of Sports Medicine 2001, 29(3):304-310.

13. Williams D: Lower Extremity Mechanics and Injury Patterns in Runners with Pes Cavus and Pes Planus. In Ph.D Thesis University of Delaware; 2000.

14. Cowan D, Jones B, Robinson J: Foot Morphologic Characteristics and Risk of Exercise-Related Injury. Archives of Family Medicine 1993, 2(7):773.

15. McClay I: The Evolution of the study of the Mechanics of Running. Journal of the American Podiatric Medical Association 2000, 90(3): | 33-| 48.

16. Bennet J, Reinking M, Pluemer B, Pentel A, Seaton M, Killian C: Factors Contributing to the Development of Medial Tibial Stress Syndrome in High School Runners. J Orthop Sports Phys Ther 200I, 3 I(9):504-5 I0.

17. Willems T, DeClerq D, Delbaere K, Vanderstraeten G, DeCock A, Witvrouw E: A prospective study of gait related risk factors for exercise-related lower leg pain. Gait \& Posture 2006, 23:91-98.

18. Bandholm T, Boysen L, Haugaard S, Zebis M, Bencke J: Foot Medial Longitudinal-Arch Deformation During Quiet Standing and Gait in Subjects with Medial Tibial Stress Syndrome. The Journal of Foot and Ankle Surgery 2008, 47(2):89-95.

19. Irving D, Cook J, Menz H: Factors Associated with Chronic Plantar Heel Pain: A Systematic Review. Journal of Science and Medicine in Sport 2006, 9: I |-22.

20. Rome K, Howe T, Haslock I: Risk Factors Associated With the Development of Plantar Heel Pain in Athletes. The Foot 200I, I I:I I 9- I 25.

21. Kibler W, Goldberg C, Chandler T: Functional biomechanical deficits in running athletes with plantar fasciitis. The American Journal of Sports Medicine I99I, I9(I):66-7I.

22. Irving D, Cook J, Young M, Menz H: Obesity and Pronated Foot Type May Increase the Risk of Chronic Plantar Heel Pain: A Matched Case-Control Study. BMC Musculoskeletal Disorders 2007, 8(4I):

23. D'hondt N, Struijs P, Kerkhoffs G, Verheul C, Lysens R, Aufdemkampe G, van Dijk C: Orthotic Devices for Treating Patellofemoral Pain Syndrome. Cochrane Database Syst Rev 2002:CD002267.

24. Gross M, Foxworth J: The role of foot orthoses as an intervention for patellofemoral pain. J Orthop Sports Phys Ther 2003, 33(I I):66I-670.

25. Hetsroni I, Finestone A, Milgrom C, Ben Sira D, Nyska M, RadevaPetrova D, Ayalon M: A Prospective Biomechanical Study of the Association Between Foot Pronation and the Incidence of Anterior Knee Pain Among Military Recruits. Journal of Bone and Joint Surgery 2006, 88(7):905-908.

26. Lun V, Meeuwisse W, Stergiou P, Stefanyshyn D: Relationship Between Running Injury and Static Lower Limb Alignment 
in Recreational Runners. British Journal of Sports Medicine 2004, 38:576-580.

27. Thijs Y, van Tiggelen D, Roosen P, De Clerq D, Witvrouw E: A Prospective Study on Gait-Related Intrinsic Risk Factors for Patellofemoral Pain. Clin J Sport Med 2007, I7(6):437-445.

28. Duffey M, Martin D, Cannon W, Craven T, Messier S: Etiologic Factors Associated with Anterior Knee Pain in Distance Runners. Medicine \& Science in Sports \& Exercise 2000, 32(II): $1825-1832$.

29. Hampton S, Maffucci R, Powers C: Rearfoot Posture in Subjects with Patellofemoral Pain. J Orthop Sports Phys Ther 1995, 22(4): $155-160$.

30. Powers C, Chen P, Reischl S, Perry J: Comparison of Foot Pronation and Lower Extremity Rotation in Persons With and Without Patellofemoral Pain. Foot Ankle Int 2002, 23(7):634-640.

31. Ballas M, Tytko J, Cookson D: Common Overuse Running Injuries: Diagnosis and Management. American Family Physician 1997, 55(7):2473-2485.

32. Taunton J, Ryan M, Clement D, McKenzie D, Lloyd-Smith D, Zumbo B: A Retrospective Case-Control Analysis of 2002 Running Injuries. British Journal of Sports Medicine 2002, 36:95-101.

33. Tuan K, Wu S, Sennet B: Stress Fractures in Athletes: Risk Factors, Diagnosis, and Management. Orthopedics 2004, 27(6):583-59।.

34. Landorf K, Keenan A: Do Foot Orthoses Prevent Injury? In Evidence-Based Sports Medicine 2nd edition. Edited by: MacAuley D, Best T. Malden: Blackwell; 2007.

35. Collins N, Bisset L, McPoil T, Vicenzino B: Foot Orthoses in Lower Limb Overuse Conditions: A Systematic Review and MetaAnalysis. Foot and Ankle International 2007, 28(3):396-4I2.

36. Rome K, Handoll H, Ashford R: Interventions for preventing and treating stress fractures and stress reactions of bone of the lower limbs in young adults. Cochrane Database Syst Rev 2005:CD000450.

37. Larsen K, Weidich F, Leboeuf-Yde C: Can custom-made biomechanic shoe orthoses prevent problems in the back and lower extremities? A randomized, controlled intervention trial of I 46 military conscripts. Journal of Manipulative and Physiological Therapeutics 2002, 25:326-331.

38. Eng J, Pierrynowski M: Evaluation of soft foot orthotics in the treatment of patellofemoral pain syndrome. Physical Therapy 1993, 73:62-70.

39. Johnston L, Gross M: Effects of foot orthoses on quality of life for individuals with patellofemoral pain syndrome. J Orthop Sports Phys Ther 2004, 34(8):440-448.

40. Saxena A, Haddad J: The effect of foot orthoses on patellofemoral pain syndrome. Journal of the American Podiatric Medical Association 2003, 93(4):264-271.

4I. Landorf K, Keenan A, Herbert R: Effectiveness of different types of foot orthoses for the treatment of plantar fasciitis. Journal of the American Podiatric Medical Association 2004, 94(6):542-549.

42. Crawford F, Thomson C: Interventions for treating plantar heel pain. Cochrane Database Syst Rev 2003:CD0004I6.

43. Landorf $K$, Keenan A, Herbert R: Effectiveness of foot orthoses to treat plantar fasciitis: a randomized trial. Archives of Internal Medicine 2006, 166:1305-1310.

44. Payne C, Chuter V: The Clash Between Theory and Science on the Kinematic Effectiveness of Foot Orthoses. Clin Podiatr Med Surg 200I, I8(4):705-7I3

45. Nigg B, Nurse M, Stefanyshyn D: Shoe inserts and orthotics for sport and physical activities. Medicine \& Science in Sports \& Exercise 1999, 3 I (7):S42I-S428.

46. Razeghi M, Batt M: Biomechanical analysis of the effect of orthotic shoe inserts: a review of the literature. Sports Medicine 2000, 29(6):425-438.

47. Ferber R: The influence of custom foot orthoses on lower extremity running mechanics. International SportMed Journal 2007, 8(3):97-106.

48. Clinical Guidelines For Orthotic Therapy Provided By Podiatrists. Australian Podiatry Council, Brunswick East, Victoria; 1998.

49. Downs $\mathrm{S}, \mathrm{Black} \mathrm{N}$ : The feasability of creating a checklist for the assessment of the methodological quality both of ransomised and non-randomised studies of health care interventions. J Epidemiol Community Health I998, 52(6):377-384
50. Richards ]: Biomechanics in Clinic and Research. Philadelphia: Churchill Livingstone; 2008

5I. Butler R, Davis I, Laughton C, Hughes M: Dual-function foot orthosis: Effect on shock and control of rearfoot motion. Foot Ankle Int 2003, 24(5):410-414.

52. Dixon SJ: Influence of a commercially available orthotic device on rearfoot eversion and vertical ground reaction force when running in military footwear. Mil Med 2007, I72(4):446-450.

53. Laughton CA, Davis IM, Hamill J: Effect of strike pattern and orthotic intervention on tibial shock during running. Journal of Applied Biomechanics 2003, 19(2): I53-168.

54. MacLean C, Davis IM, Hamill J: Influence of a custom foot orthotic intervention on lower extremity dynamics in healthy runners. Clin Biomech (Bristol, Avon) 2006, 21 (6):623-630.

55. Mundermann A, Nigg BM, Humble RN, Stefanyshyn DJ: Foot orthotics affect lower extremity kinematics and kinetics during running. Clin Biomech (Bristol, Avon) 2003, I 8(3):254-262

56. Stackhouse $C L$, Davis IM, Hamill J: Orthotic intervention in forefoot and rearfoot strike running patterns. Clin Biomech (Bristol, Avon) 2004, 19(I):64-70

57. Williams DS 3rd, McClay Davis I, Baitch SP: Effect of inverted orthoses on lower-extremity mechanics in runners. Med Sci Sports Exerc 2003, 35(I2):2060-2068.

58. Dixon S, McNally K: Influence of orthotic devices prescribed using pressure data on lower extremity kinematics and pressures beneath the shoe during running. Clinical Biomechanics 2008.

59. Nigg BM, Stergiou P, Cole G, Stefanyshyn D, Mundermann A, Humble $\mathrm{N}$ : Effect of shoe inserts on kinematics, center of pressure, and leg joint moments during running. Med Sci Sports Exerc 2003, 35(2):3|4-319.

60. McPoil TG, Cornwall MW: Rigid versus soft foot orthoses. A single subject design. J Am Podiatr Med Assoc 1991, 8 I ( 2 2):638-642.
Publish with Biomed Central and every scientist can read your work free of charge

"BioMed Central will be the most significant development for disseminating the results of biomedical research in our lifetime. "

Sir Paul Nurse, Cancer Research UK

Your research papers will be:

- available free of charge to the entire biomedical community

- peer reviewed and published immediately upon acceptance

- cited in PubMed and archived on PubMed Central

- yours - you keep the copyright
BioMedcentral 